\title{
French Health Technology Assessment of Antineoplastic Drugs Indicated in the Treatment of Solid Tumours: Perspective for Future Trends
}

\author{
Christos Chouaid $^{1,2} \cdot$ Isabelle Borget $^{3,4,5}$ • Eric Braun ${ }^{6}$ • Marie-Laure Bazil ${ }^{6}$. \\ Dominique Schaetz $^{6} \cdot$ Cécile Rémuzat $^{7} \cdot$ Mondher Toumi $^{8}$
}

Published online: 1 February 2016

(C) The Author(s) 2016. This article is published with open access at Springerlink.com

\begin{abstract}
Background France is one of the European countries that spend the most on oncology drugs. To keep pharmaceutical expenditure under control, Health Authorities highly scrutinize market access of costly medicines.

Objective To assess current and future trends in French health technology assessment (HTA) of antineoplastic drugs indicated in the treatment of solid tumours.

Methods A review of the SMR and ASMR drivers of the Transparency Committee (CT) opinions issued for antineoplastic drugs indicated in the treatment of solid tumours and approved between 2009 and 2014 was performed to assess current trends in French health technology assessment (HTA), complemented by an expert board consultation to capture the critical issues on the future of antineoplastic drugs HTA.
\end{abstract}

Electronic supplementary material The online version of this article (doi:10.1007/s11523-015-0411-8) contains supplementary material, which is available to authorized users.

Mondher Toumi

mondher.toumi@emaud.org

1 INSERM UMR U955, Faculté de Médecine, Université Paris Est (UPEC), F-94010, Créteil, France

2 Département de Pneumologie et Pathologie Professionnelle, Centre Hospitalier Intercommunal, DHU-ATVB, F-94010, Créteil, France

3 Unité de Biostatistique et d'Epidemiologie, Institut Gustave Roussy, 94805, Villejuif, France

4 Méthodologie et Epidémiologie Clinique en Oncologie Moléculaire, Equipe 2, INSERM U1018, Centre de recherche en épidémiologie et
Results Thirty-one drugs indicated for the treatment of solid tumours were identified (77 \% targeted therapies). Initial CT assessments were available for 26 drugs. Four key items in the CT assessment were identified: 1) Clinical trial methodology; 2) Acceptance of progression-free survival (PFS) as a valuable endpoint; 3) Transferability of clinical trials in clinical practice; 4) Unpredictability of CT decisions. Experts raised the important development of personalised medicines in oncology and key challenges for oncology products to generate information expected from HTA perspective.

Conclusion The French system remains committed to its values and philosophy (access of all innovations for everybody) which are threatened by the increasing launch of innovative therapies and budget constraint. Both HTA decision framework evolution and revision of the current pricing process should be considered in France to cope with these new challenges.

santé des populations, Institut Gustave Roussy, 94805 , Villejuif, France

5 Groupe de Recherche et d'Accueil en Droit et Économie de la Santé (GRADES), Faculté de Pharmacie, Université Paris-Sud, 92296, Châtenay-Malabry CEDEX, France

6 Départment Market Access, Janssen, 92130, Issy-Les-Moulineaux, France

7 Creativ-Ceutical, 75008, Paris, France

8 Laboratoire de Santé Publique, Faculté de Médecine, Aix-Marseille Université, 13015, Marseille Cedex, France 


\section{Key Points}

The French system remains committed to its values and philosophy (access of all innovations for everybody) which are threatened by the increasing launch of innovative therapies and budget constraint.

French HTA analysis decision model will have to evolve to cope with the new challenges raised by oncology drugs.

More coordination is expected between European regulators, payers and pharma ceutical companies for evidence generation.

\section{Introduction}

Cancer is a public health issue that affects 3 million people aged 15 years and over in France with approximately 355,000 new cases and 148,000 cancer-related deaths in 2012 [1]. Over the period between 2005 and 2009, cancer was the first cause of deaths in men and the second cause of deaths in women [2], with $33 \%$ and $24 \%$ attributed deaths, respectively [1]. Among all cancers, solid tumours (main solid cancers include: prostate, testis, breast, bladder, uterine body, uterine cervix, ovary, pancreas, kidney, lip/oral cavity/pharynx, larynx, melanoma, liver, lung, thyroid, oesophagus, stomach, colon-rectum, central nervous system) account for approximately $83 \%$ of all cancers and caused around $68 \%$ of all cancer-related deaths in 2012 [3]. The four main cancers are prostate cancer, breast cancer, colorectal cancer and lung cancer [1].

Cancer imposes an enormous financial burden to society, estimated in France at $€ 17$ billion and the cancer-related healthcare cost was estimated at $€ 7$ billion, i.e. $3 \%$ of the total health-care expenditure [4]. Drug costs represented around $43 \%$ of cancer-related healthcare costs (around $€ 3$ billion), making France one of the EU countries that spends the most on oncology drugs. The mean cancer drug cost per inhabitant was estimated at $€ 47$ in France, whereas it represented $€ 27$ in Italy, $€ 33$ in Germany and Spain, $€ 17$ in UK and $€ 28$ in EU27 [4].

The high prices of antineoplastic drugs opened debates among French Health Authorities, scientific and public community; oncology was pointed at as a therapeutic area raising economic and ethical concerns. Moreover, these debates have been widely covered by media [5-19]. In the third national Cancer Plan (2014-2019) [20], three key actions related to antineoplastic drugs are planned to reshape assessment criteria of anticancer drugs, to enhance better use of anticancer drugs, and to develop horizon scanning to ensure sustainable access to innovative therapies on the long term.

As part of an effort to confront the deficit of the National Health Insurance and press it to recover a healthy financial balance, the successive annual social security funding laws implemented since 1996 in France provided measures to contain drug expenditure such as price cuts, generic incentives and additional taxes for pharmaceutical companies [21]. Among these measures, one important change in the French market access environment was the introduction of health economic evaluations (Social Security Funding Law for 2012 [22]). Moreover, recent measures showed higher scrutiny of Health Authorities on market access pathways for potentially costly medicines, targeting the early access scheme for innovative medicines (Autorisation Temporaire d'Utilisation, ATU) [23, 24], or the funding pathway of costly medicines on top of Diagnosis Related Groups (DRG) tariffs known as "Liste en sus" system [16, 24-27].

In France, the assessment of drugs is carried out by the Transparency Committee (Commission de la TransparenceCT), which is one of the scientific committees of the French National Authority for Health (Haute Autorité de Santé, HAS). This Committee evaluates the new medicines for which there is a request for inclusion on a positive list of reimbursed products and issues opinions based essentially on the review of the medical evidence available. The CT is in charge of assessing the Actual Benefit (Service Médical Rendu, SMR) and the Improvement in Actual Benefit (Amélioration du Service Médical Rendu, ASMR) of the new medicines. The SMR is set based on the severity of the disease, the efficacy and safety, the position of the treatment in the therapeutic strategy, the impact on public health and type of treatment (preventive, curative or symptomatic). The ASMR is set based on the assessment versus relevant comparators by indication and/or therapeutic strategy. Drug price setting is established by the Economic Committee on Healthcare Products (Comité Economique des Produits de Santé, CEPS) after negotiation with the drug company. ASMR is one of the key items taken into account during price setting. The reimbursement rate is fixed by a decision of the National Healthcare Insurances (Union Nationale des Caisses d'Assurance Maladie, UNCAM) based on SMR. The Health Ministry makes the final decision regarding whether or not the drug will be registered on the list of reimbursable medicines. This registration is valid for 5 years. At the end of this period or at any time when significant new information becomes available, the CT re-evaluates the SMR and ASMR levels. For drugs that are likely to have a significant impact on the health insurance budget or for those claiming an ASMR I, II or III, health economic assessment is required and is performed by the Economic and Public Health Assessment Committee (Commission Evaluation Economique et de Santé Publique, CEESP).

Over the past few years, a shift has been seen in the appreciation of Actual Benefit (Service Médical Rendu, SMR) and the Improvement in Actual Benefit (Amélioration du Service Médical Rendu, ASMR) by the Transparency Committee (Commission de la Transparence, CT). In the evaluation of the SMR, the CT requires more and more evidence on the 
drug efficacy while the criterion severity of the disease is less considered. In the evaluation of the ASMR, the CT is increasingly considering the effect size [28]. Of note, head-to-head trials were stated in the Law $n^{\circ} 2011-2012$ related to the reinforcement of the health safety of drugs and health products as required to get reimbursement when reference treatment is available in France (application decree still pending) [23].

In the past, cancer was perceived as a lethal disease with limited treatment options and oncology area enjoyed from a relatively lenient pricing and reimbursement environment compared to other therapeutic areas (e.g. straight acceptance of non-comparative single arm trials, surrogate endpoints by health technology assessment agencies).

This study aims to conduct a review of the SMR and ASMR drivers of the CT opinions of antineoplastic drugs indicated for the treatment of solid tumours approved in the last 6 years to assess current trends in French health technology assessment (HTA), to confront experts with the outcomes of this review and discuss the foreseen challenges for HTA of future antineoplastic medicines in France.

\section{Methods}

A review of the CT opinions issued for all antineoplastic drugs indicated in the treatment of solid tumours and approved over the last 6 years (2009-2014) was performed (cut-off date: 24 February 2015). The secondary research was complemented by an expert board consultation to capture the critical issues on the future of antineoplastic drugs' HTA.

\subsection{Drug Selection and Review of the CT Opinions}

We used the European Medicines Agency (EMA) website to identify medicines having a centralized marketing authorization (MA) between 2009 and 2014. All drugs approved before 2009 and for which there has been an extension of indication during the period of interest, as well as generics and biosimilars were excluded from our search.

We identified all drugs indicated in the treatment of solid tumours and we extracted from the HAS website the related CT opinions, including re-assessment, and extensions of indications opinions. The collected data were compiled into an extraction grid (Fig. S1 in supplementary file).

Based on the extraction, descriptive statistics and qualitative analysis were performed. Products that were scored ASMR I, II, III were considered as presenting an additional benefit acknowledged by the CT. Particular attention was paid to the rationale for acknowledging an additional benefit. We randomly looked over the $\mathrm{CT}$ opinions in a group of 5 in an iterative way. We identified and grouped according to similarities the reasons for acknowledging or not the additional benefit.
Data were extracted by a researcher experienced in extraction of HTA reports and a quality control was performed by a research manager experienced in reviewing HTA reports in oncology and having a long experience of $\mathrm{CT}$ processes and opinions. For qualitative analysis, we believed this methodology allows well for controlling the risk of errors.

\subsection{Expert Board Meeting}

Five experts with significant experience in HTA decision making in oncology (Fig. S2 in supplementary file) were recruited to participate in a board meeting to review the CT opinions extraction and provide their insights on oncology HTA trends in France. The expert board aimed to inform the opinions of the CT as the process is deliberative and facts needed to be put in their context. Moreover, as HTA is an extremely dynamic field, the experts were requested to elaborate on the future of HTA of oncology solid tumour products.

A pre-meeting questionnaire based on the findings of the CT opinions review was sent to the experts and filled in before the board meeting to prepare and optimize interactions. The questionnaire was structured around eight sections: general considerations in HTA trends, clinical trial methodology, transferability of clinical trial data to clinical practice, clinical trial efficacy data, specificities of antineoplastic drugs (indication, targeted therapies, route of administration), health economics assessment, price of antineoplastic drugs, as well as any additional comments the expert would make. A copy of the questionnaire is available from the authors upon request. The completed questionnaires received from the experts were consolidated in a presentation for the meeting.

The board meeting took place over half a day and was moderated by an expert in HTA and oncology. The meeting was structured around the key themes identified through the answers of the experts to the pre-meeting questionnaire as well as the $\mathrm{CT}$ opinions review outcomes.

\section{Results}

\subsection{Selection of Drugs Through EMA Website}

The search through the EMA website retrieved 297 new treatments that were granted a MA between 2009 and 2014. Of these, 53 were oncology drugs with 31 indicated for the treatment of solid tumours (Fig. 1, Table 1).

From the selected antineoplastic drugs targeting solid cancers, 26 drugs were granted a standard MA and five drugs were approved under conditional approval (one conditional MA switched then to standard MA). Four drugs of these 31 drugs were granted an orphan drug status and 19 drugs had an ATU. 
Fig. 1 Drug selection results

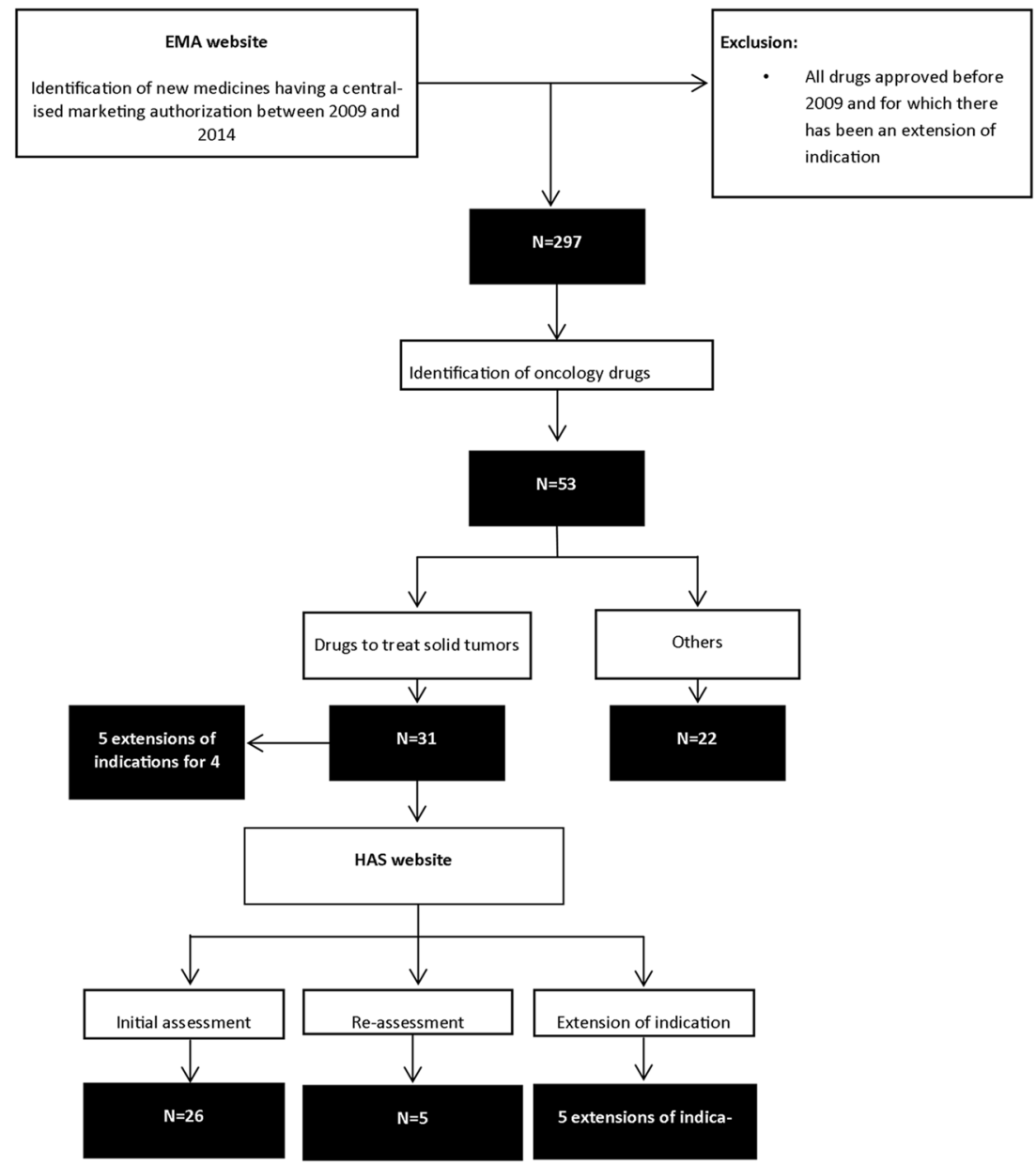

The main characteristics of the selected drugs are presented in Fig. 2. Two drugs were indicated in different types of cancer and three drugs had more than one indication for the same type of cancer. With a total of six drugs, prostate cancer was the most frequent indication. Oral route $(55 \%)$ was the most frequent, followed by intravenous route $(38 \%)$. Targeted therapies represented $77 \%$ of all drugs.

\subsection{Review of CT Opinions}

Initial CT assessments were available for 26 drugs. About $35 \%$ of these drugs were indicated as first-line therapies only, other drugs being indicated as first-line and second-line therapies, as second-line therapies or beyond. Four drugs had an extension of indication on the considered period with available CT opinions. Six medicines went through CT reassessments (Fig. 1, Table 2).

The average period between MA and the CT opinion was 6.3 months (range: $2 ; 20$ ) and 7.7 months (range: $2 ; 33$ ) between the CT opinion and the price publication. Nineteen drugs went through an ATU with a start date available for nine of them. Time between ATU and MA was 24.2 months in average (range: $1 ; 106)$.
ASMR and SMR ratings were reported in Table 2 and Fig. 3. Two of the three drugs re-assessed by the CT were granted a better score. Cabazitaxel was granted an ASMR III (2012) versus ASMR IV (2011) following new data provided by the company and considering that cabazitaxel was not different from recently approved therapy in the same indication which was granted an ASMR III ${ }^{1}$. Pazopanib was granted a lower SMR in one subgroup of patients, with an ASMR V in this subgroup (2013).

ATU status did not impact the ASMR score (Fig. 4).

Efficacy (effect size)/safety ratio as assessed by the CT (low, moderate or high) generally predicted SMR ratings (i.e. a substantial SMR was always correlated with high efficacy/safety ratio while a moderate, low or insufficient SMR was correlated with moderate or low efficacy/safety ratio), but not ASMR ratings (Fig. 5).

\footnotetext{
${ }^{1}$ Abiraterone acetate had been assessed by the $\mathrm{CT}$ in a similar indication following initial assessment of cabazitaxel and granted ASMR III. Considering initial resistance data for hormone therapy with abiraterone acetate observed in some patients and new submitted data, the therapeutic benefit of cabazitaxel was considered to be of the same order as that of abiraterone acetate.
} 
Table 1 List of selected drugs indicated in solid tumours

\begin{tabular}{|c|c|c|c|}
\hline INN & Brand name & MA date & Tumour type \\
\hline Abiraterone acetate & Zytiga $^{\circledR}$ & $05 / 09 / 2011$ & Prostate \\
\hline Afatinib & Giotrif $^{\circledR}$ & $25 / 09 / 2013$ & Lung \\
\hline Aflibercept & Zaltrap $^{\circledR}$ & $01 / 02 / 2013$ & Colorectal tract \\
\hline Axitinib & Inlyta $^{\circledR}$ & $03 / 09 / 2012$ & Kidney \\
\hline Cabazitaxel & Jevtana $^{\circledR}$ & $17 / 03 / 2011$ & Prostate \\
\hline Cabozantinib & Cometriq $^{\circledR}$ & $21 / 03 / 2014$ & Thyroid \\
\hline Catumaxomab & Removab $^{\circledR}$ & $20 / 04 / 2009$ & Ascites \\
\hline Crizotinib & Xalkori $^{\circledR}$ & $23 / 10 / 2012$ & Lung \\
\hline Dabrafenib & Tafinlar ${ }^{\circledR}$ & $26 / 08 / 2013$ & Skin \\
\hline Degarelix & Firmagon $^{\circledR}$ & $17 / 02 / 2009$ & Prostate \\
\hline Enzalutamide & Xtandi ${ }^{\circledR}$ & $21 / 06 / 2013$ & Prostate \\
\hline Eribulin & Halaven $^{\circledR}$ & $17 / 03 / 2011$ & Breast \\
\hline Everolimus & Afinitor ${ }^{\circledR}$ & 03/08/2009 & Breast, pancreas and kidney \\
\hline Gefitinib & Iressa $^{\circledR}$ & $24 / 06 / 2009$ & Lung \\
\hline Ipilimumab & Yervoy ${ }^{\circledR}$ & $13 / 07 / 2011$ & Skin \\
\hline Mifamurtide & Mepact $^{\circledR}$ & $06 / 03 / 2009$ & Bones \\
\hline Nintedanib & Vargatef ${ }^{\circledR}$ & $21 / 11 / 2014$ & Lung \\
\hline Olaparib & Lynparza $^{\circledR}$ & $16 / 12 / 2014$ & Ovaries, fallopian tubes and peritonea \\
\hline Pazopanib & Votrient ${ }^{\circledR}$ & $14 / 06 / 2010$ & Kidney and soft-tissue \\
\hline Pertuzumab & Perjeta $^{\circledR}$ & $04 / 03 / 2013$ & Breast \\
\hline Radium Ra223 dichloride & Xofigo ${ }^{\circledR}$ & $13 / 11 / 2013$ & Prostate \\
\hline Ramucirumab & Cyramza $^{\circledR}$ & $19 / 12 / 2014$ & Gastro-oesophageal tract \\
\hline Regorafenib & Stivarga $^{\circledR}$ & $26 / 08 / 2013$ & Colorectal tract \\
\hline Sipuleucel-T & Provenge ${ }^{\circledR}$ & $06 / 09 / 2013$ & Prostate \\
\hline Tegafur/Gimeracil/Oteracil & Teysuno ${ }^{\mathbb{R}}$ & $14 / 03 / 2011$ & Gastro-oesophageal tract \\
\hline Trametinib & Mekinist $^{\circledR}$ & $30 / 06 / 2014$ & Skin \\
\hline Trastuzumab emtansine & Kadcyla $^{\circledR}$ & $15 / 11 / 2013$ & Breast \\
\hline Vandetanib & Caprelsa $^{\circledR}$ & $17 / 02 / 2012$ & Thyroid \\
\hline Vemurafenib & Zelboraf $^{\circledR}$ & $17 / 02 / 2012$ & Skin \\
\hline Vinflunine & Javlor ${ }^{\circledR}$ & $21 / 09 / 2009$ & Urothelial tract \\
\hline Vismodegib & Erivedge $^{\circledR}$ & $12 / 07 / 2013$ & Basal cells \\
\hline
\end{tabular}

\subsection{Qualitative Analysis of CT Assessment}

The qualitative analysis of the CT opinions allowed identifying four key items of importance in the CT assessment: 1) The clinical trial methodology; 2) The acceptance of the progression-free survival (PFS) as a valuable endpoint, while overall survival remains a key endpoint; 3 ) The transferability of clinical trials in clinical practice; 4) The unpredictability of CT decisions.

On top of that, the targeted specificity of the drug was considered by the CT for ASMR score granting. For example, the targeted specificity of vemurafenib, indicated in welldefined population BRAF V600 mutation-positive unresectable or metastatic melanoma, was one criteria considered by the $\mathrm{CT}$ in the decision of awarding an ASMR III in 2012.

\subsubsection{Importance of Clinical Trial Methodology}

The conduct of a clinical trial versus active comparator, when available, is an important criterion for the CT. For example, in 2011, the CT attributed an insufficient SMR to pazopanib, indicated in advanced renal cell carcinoma, due to absence of any direct comparison against the already available medicinal products. The clinical data submitted were based on one pivotal placebo-controlled study and one indirect comparison. The indirect comparison was considered as uninformative by the $\mathrm{CT}$ because of wide confidence intervals, poor indirect comparison network, heterogeneity not really assessable and source information based on intermediate analysis, potentially biased.

However, the CT may be flexible when there are no therapeutic alternatives. For example, vismodegib, indicated in 
Fig. 2 Drugs characteristics: tumour type (a), number of indication (b), administration mode (c), pharmacological class (d). Note: Data reported for 31 drugs indicated in solid tumours having centralized EU authorisation, 2009-2014. *1 drug targeting 3 types of cancer and 1 drug targeting 2 types of cancer
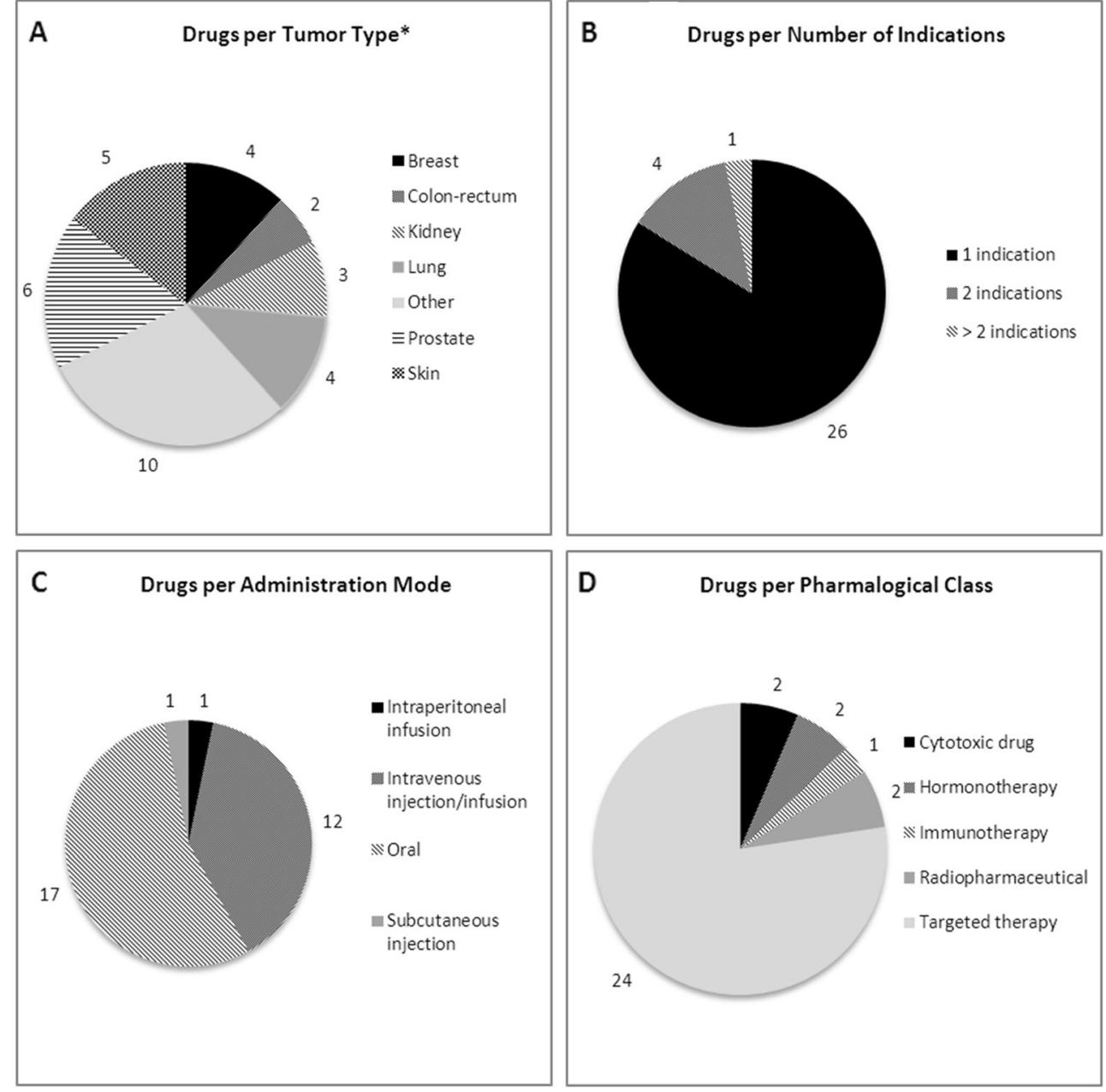

advanced basal cell carcinoma and for which no clinically appropriate comparator was available, got scored with a substantial SMR and an ASMR IV in 2013 despite filling a single arm phase II study.

Double-blind design was preferred by the CT when possible. For example, in its opinion released in 2013 on axitinib, indicated in advanced renal cell carcinoma, the CT pointed out the risk of bias of the open design of the study while a blinded study would have been feasible. This drug has been granted a substantial SMR and an ASMR IV. Moreover, open-label study designs are highly scrutinised by the CT as seen with catumaxomab, indicated in intraperitoneal treatment of malignant ascites, where standard therapy is not available or is no longer feasible.

The treatment regimen choice is also an important factor in the CT decisions as illustrated with the case of afatinib, indicated in non-small cell lung cancer. In its assessment in 2014, the CT highlighted that, in the pivotal study versus chemotherapy, the duration of treatment in the comparator arm has been limited to six cycles, while the afatinib group has been treated until disease progression or death. The drug got a substantial SMR and an ASMR V.
Post-hoc analyses were usually rejected by the CT. In the assessment of degarelix in 2009, indicated in advanced hormone-dependant prostate cancer, the committee did not consider the results of a post-hoc analysis of PFS. In the assessment in 2012 of tegafur/gimeracil/oteracil, indicated in advanced gastric cancer, the investigation of non-inferiority of tegafur/gimeracil/oteracil in an analysis that was not planned for in the protocol was not accepted by the CT.

Even if the study ended prematurely for positive results, upon a request of an independent review board, PFS and OS results were highly scrutinised. Two good examples of this are everolimus, indicated in advanced renal cell carcinoma and abiraterone acetate, indicated in metastatic castrationresistant prostate cancer.

Everolimus obtained a substantial SMR and an ASMR IV for a first assessment in 2010. This decision was made by the CT despite the absence of a clinically relevant comparator and the decision of an independent review board to prematurely end the study following benefit shown at interim analysis on PFS (primary endpoint), which was prolonged by 3 months in comparison with placebo. The CT pointed out that this difference was probably overestimated as the trial stopped during 


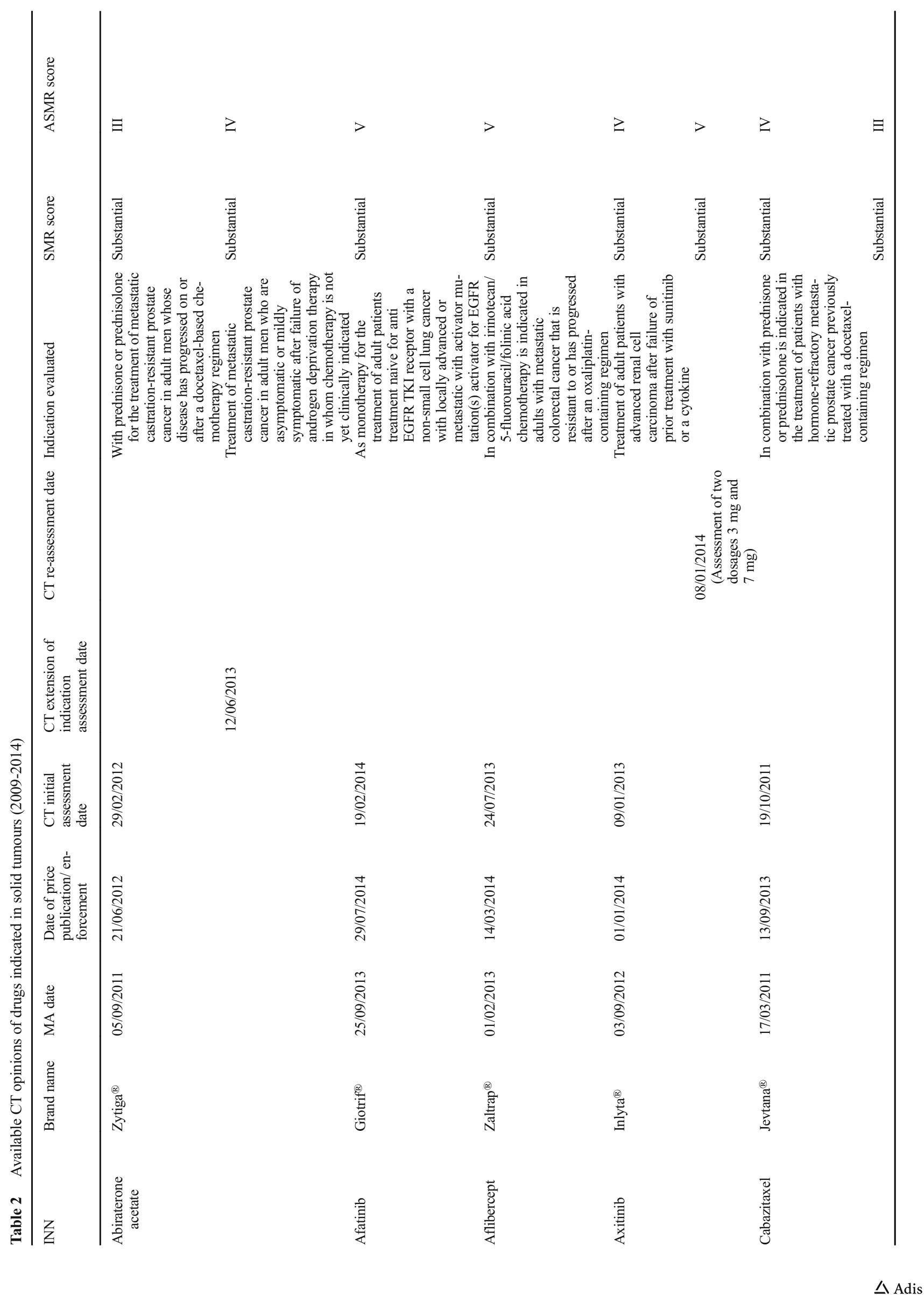




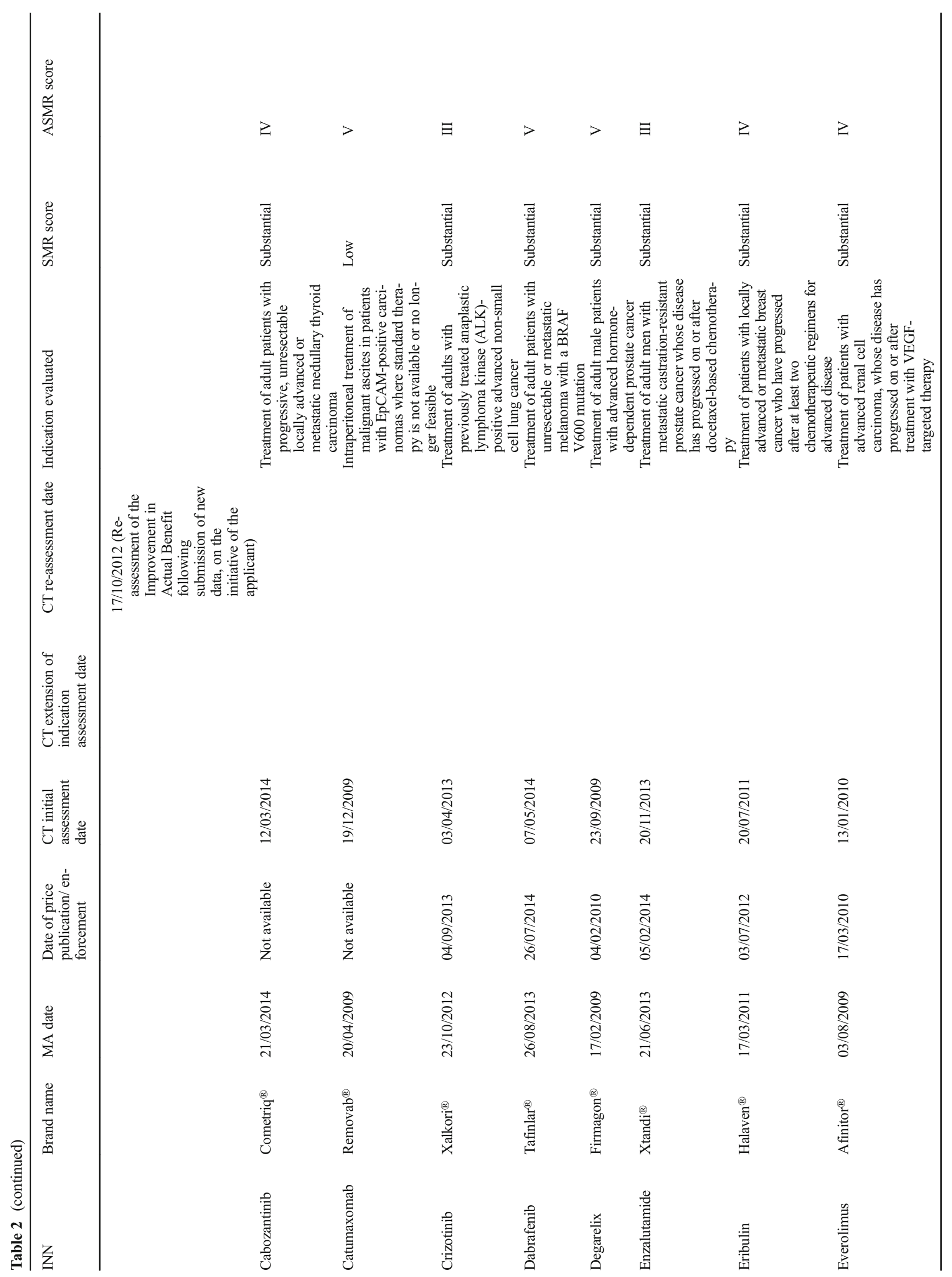




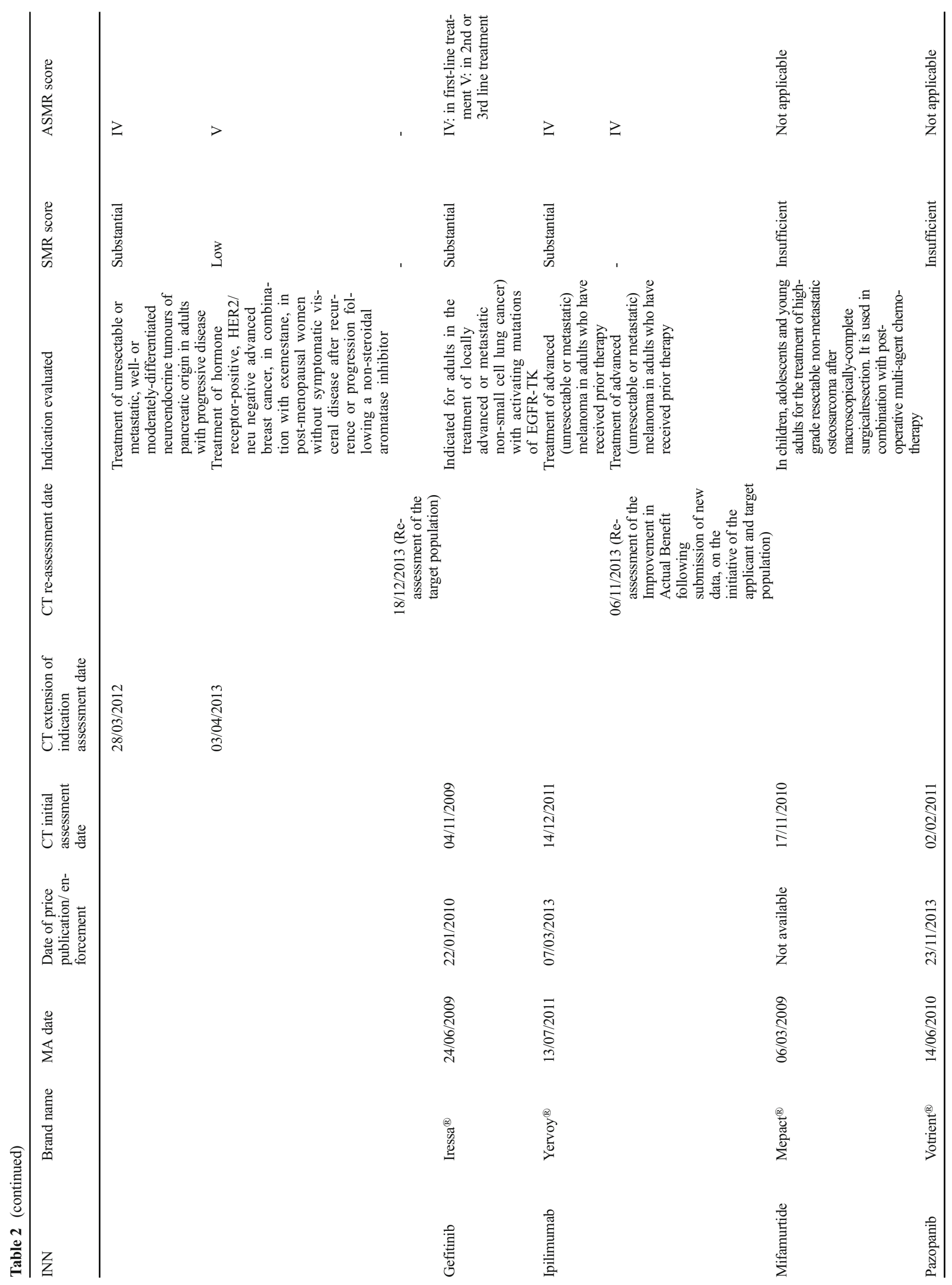




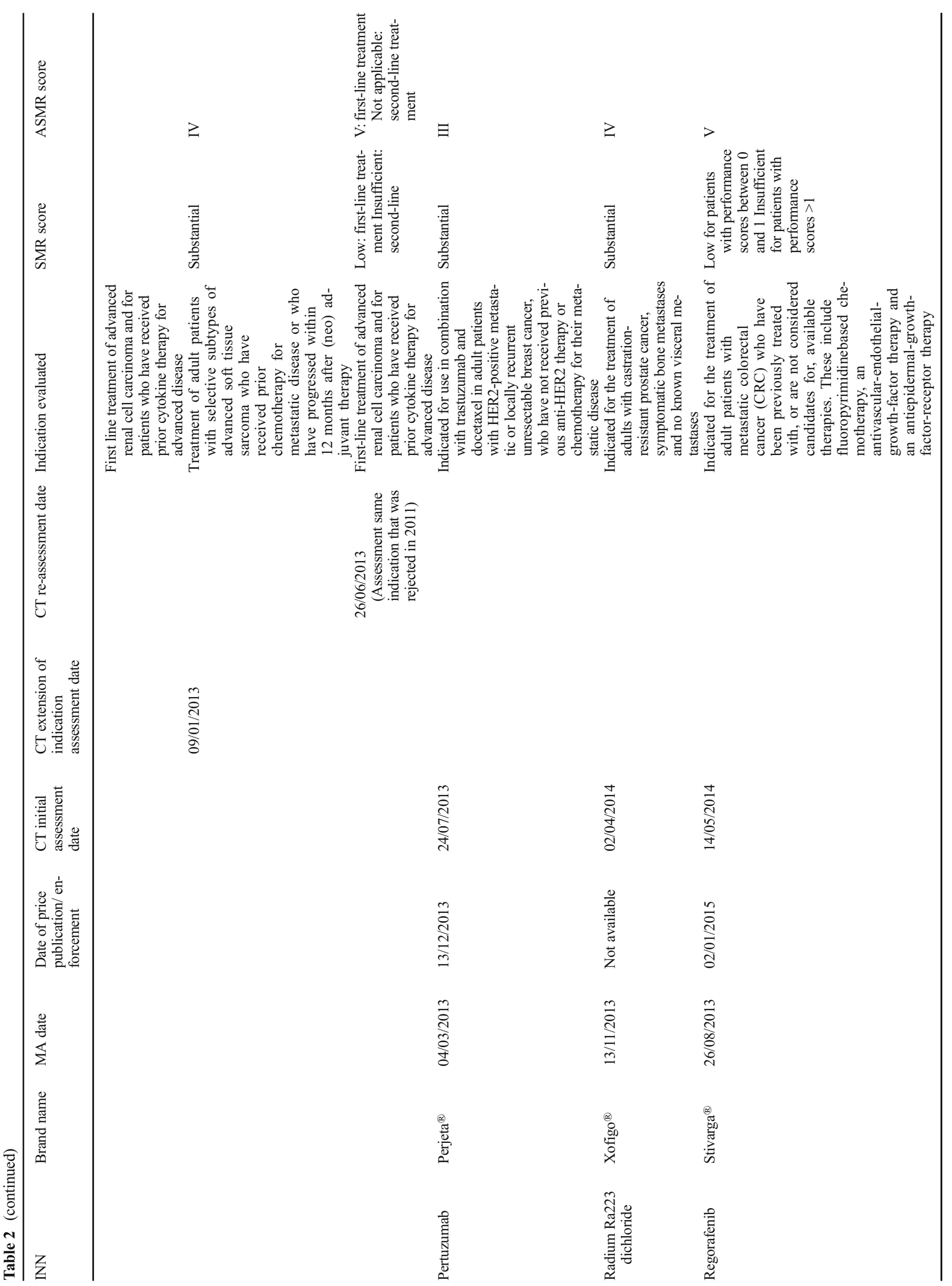




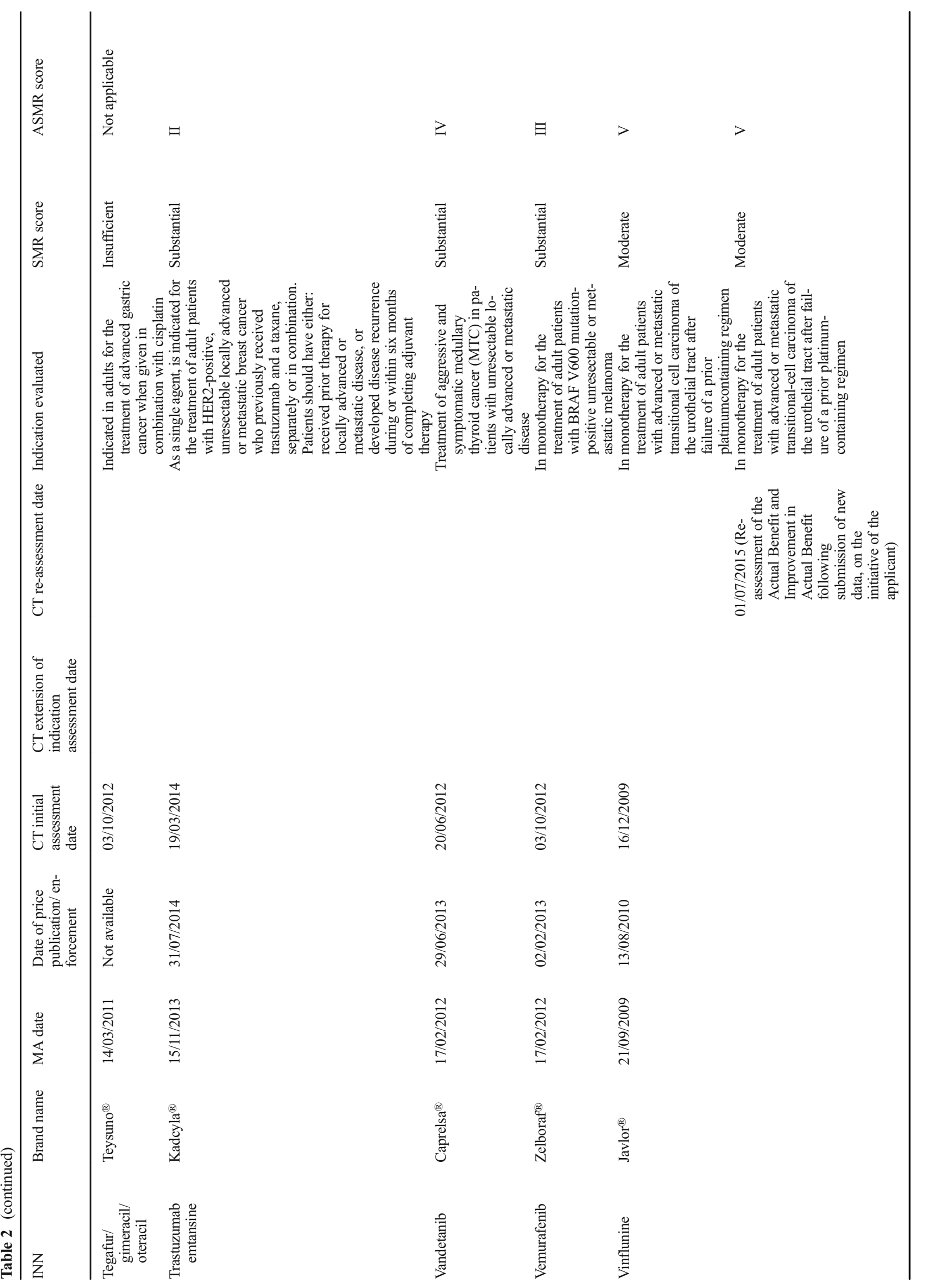


the interim analysis. At this stopping point, median OS, objective response percentage and quality of life did not reach the required level of significance and the patients of the placebo group were switched to everolimus.

The case of abiraterone acetate is very similar. This drug obtained a substantial SMR and an ASMR IV after a request for extension of indication in 2013. Also, in this case, no clinically relevant comparator was available and the study prematurely ended based on the decision of the independent review board following benefit shown at interim analysis on radiological PFS (joint primary endpoint with OS) (gain of 8.2 months versus placebo) and on secondary endpoints. The CT opinion was that the expected impact on mortality reduction is not appreciable given that the median OS did not reach the required level of significance at that stopping point.

Orphan drugs were also asked to meet the requirements of the CT regarding the adequacy and relevance of the study methodology. For instance, the SMR of mifamurtide, an orphan drug indicated in osteosarcoma, was assessed as insufficient by the CT in 2010 . The committee considered that the study presented some issues, related to the trial design, the statistical methodology and to the conduct of the study, which prevented the evaluation of the drug's effect size and place in osteosarcoma treatment.

\subsubsection{Acceptance of Progression-Free Survival (PFS) as a Valuable Endpoint, While Overall Survival Remains a Key Endpoint}

OS and PFS represented the main primary efficacy endpoints in $86 \%$ of cases.

Improvement in OS by 3 months or more versus comparator may lead to a substantial SMR and a high ASMR. For trastuzumab emanstine, indicated in breast cancer, a substantial SMR and an ASMR II were granted, driven by an improvement in the OS (5.8 month), and in the PFS (3.2 months) versus relevant comparator. However, the result analysis showed that an ASMR III might be granted even if no significant results were found for OS (Fig. 6), despite the lack of statistical benefit in OS was the reason to reject the additional benefit in other cases (e.g. cases of abiraterone acetate and everolimus described above).

PFS may be considered a valuable primary endpoint. If the drug use leads to a gain of 3 months or more in the PFS without increasing the OS, it can be awarded an ASMR IV or even III; however, additional criteria might weigh in the decision.

For example, in the case of vandetanib, indicated in medullary thyroid cancer, the results of the study showed an improvement of the PFS (primary endpoint) of 11 months versus placebo with no improvement in OS or quality of life. Vandetanib was attributed a substantial SMR and an ASMR IV in 
Fig. 3 ASMR/SMR ratings. Note: Data reported for initial CT assessment (26 drugs indicated in solid tumours, 2009-2014). *1 drug with 2 ASMR and 1 drug with 2 SMR depending on subgroup
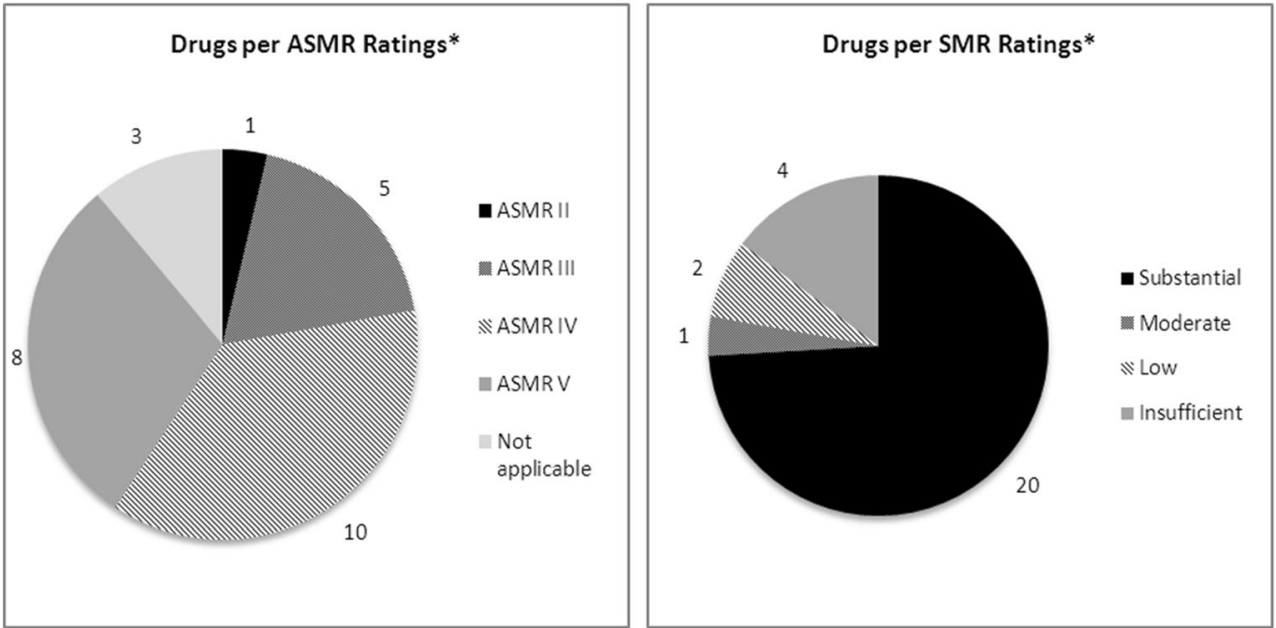

2012. The CT might have considered other criteria in its decision: the lack of approved alternative therapies available; however it was shown to induce adverse events and especially cardiac toxicity.

Another example is crizotinib, indicated in non-small cell lung cancer (NSCLC). In 2013, this drug was granted a substantial SMR and an ASMR III with a median PFS gain of 4.7 months versus standard chemotherapy and no improvement in OS. However, other criteria might have weighted in the decision, i.e. the high objective response rate obtained during the study (65.3\% vs. $19.5 \%$ in comparator arm), the fact that crizotinib was the first second line treatment for selective subtypes of advanced NSCLC (ALK + mutation) which is a serious and life-threatening condition, and that this

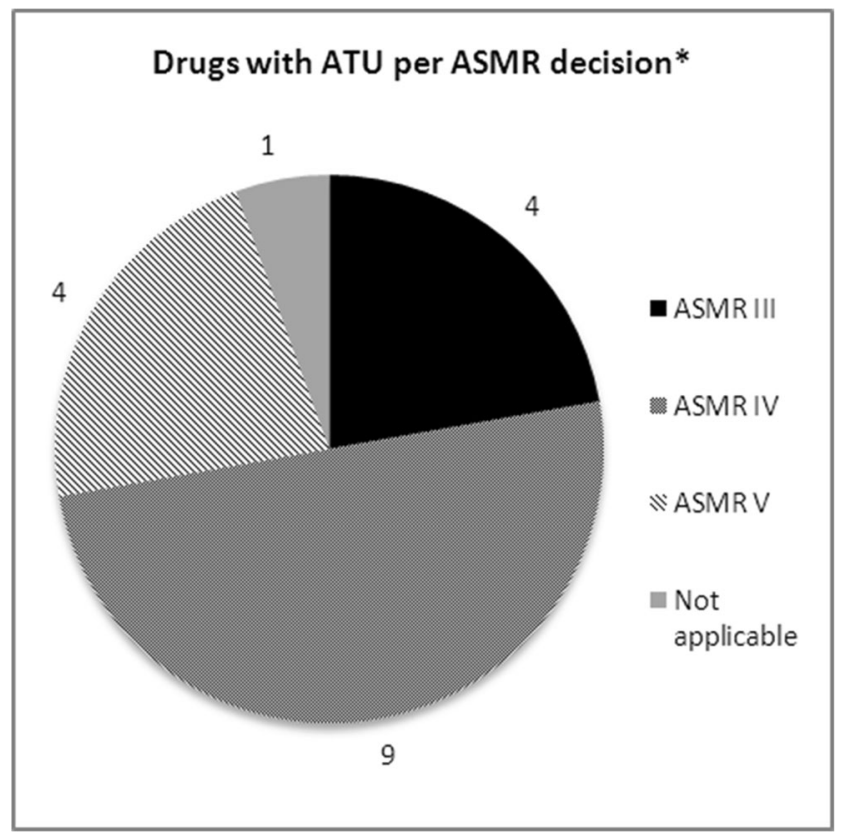

Fig. 4 ATU status and ASMR ratings. Data reported for initial CT assessment (26 drugs indicated in solid tumours, 2009-2014). * One product with two ASMR, reported two times drug might represent an oral alternative to the intravenous chemotherapy.

\subsubsection{Importance of Transferability of Clinical Trials in Clinical Practice}

The CT can be very cautious with transferability to real life of clinical data.

Inclusion/exclusion criteria of clinical trials may be reflected in the population recommended for reimbursement or influence the CT opinion.

For instance, ipilimumab, indicated in advanced melanoma, was initially scored with a substantial SMR and an ASMR IV. In a request for re-assessment based on new available data in 2013, the company has failed to get the claimed ASMR III. The CT highlighted that new data provided did not assess the effectiveness of ipilimumab in patients with failure to vemurafenib, a drug approved in 2012, so they could not assess the value of ipilimumab in this population.

In the case of gefitinib, indicated in non-small cell lung cancer, assessed in 2009, the CT highlighted that the transferability to current practice was not guaranteed due to the profile of included patients, most of whom being of Asian phenotype.

Regorafenib, indicated in metastatic colorectal cancer, has not been recommended for reimbursement by the CT in one subgroup of patients with a performance status score (ECOG) superior to 1, as one of the inclusion criteria of the submitted study was an ECOG performance status inferior or equal to 1.

Transferability in terms of standard of care is also one of the criteria taken into account. For example, for aflibercept, indicated in metastatic colorectal cancer, the CT highlighted in its assessment in 2013 that the transferability to current practice was not guaranteed due to the absence of clinical data on the comparison of aflibercept in combination, versus bevacizumab in combination. The drug was granted a substantial SMR and an ASMR V. 
Fig. 5 Efficacy/safety ratio and SMR (a) and ASMR ratings (b). Note: Data reported for initial CT assessment (26 drugs indicated in solid tumours, 2009-2014)/ 1 drug with 2 ASMR and 1 drug with 2 SMR depending on subgroup
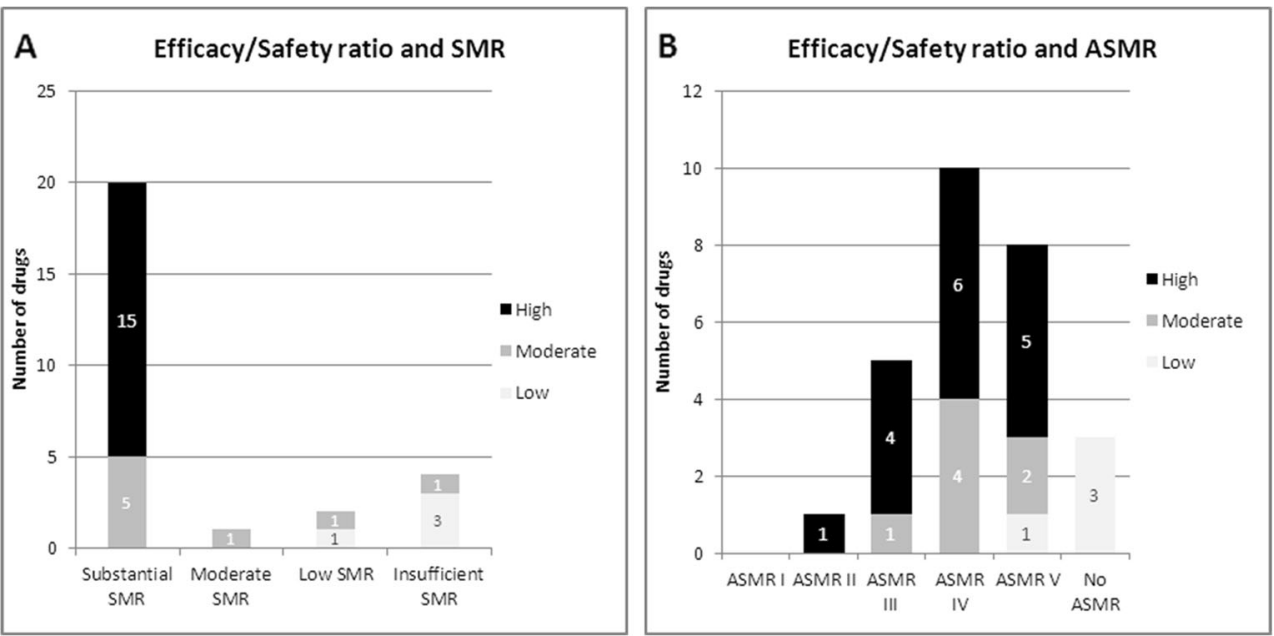

Another example is ipilimumab, indicated in previously treated advanced melanoma. This drug was granted a substantial SMR and an ASMR IV in 2011 despite the absence of approved treatments (drugs used off-label) and a gain of 3.68 months in median OS versus active comparator. The CT criticized the choice of the comparator, gp100, a product with no MA and not available on the French market.

Uncertainty on the drug safety can negatively impact the $\mathrm{CT}$ decision. For instance, for vismodegib, indicated in basal cell carcinoma, the CT highlighted in its 2013 opinion that the transferability of the study results to clinical practice was not guaranteed owing to the existing uncertainty in terms of safety (infectious, cardiovascular, neurologic and teratogenic). The drug was granted a substantial SMR and an ASMR IV.

The transferability of study results can be questioned if the study duration is not adequate. In 2009, the CT granted a substantial SMR and an ASMR V to degarelix, indicated in advanced hormone-dependant prostate cancer. The CT highlighted that the limited duration of the study (12 months) leads to uncertainty on the transferability to clinical practice.

\subsubsection{Unpredictability of CT Decisions}

While the CT sets high-level requirements for drug assessment in terms of methodological quality and expected outcomes, it may also provide unpredictable opinions, taking into account a vast array of contextual elements.

Reimbursement might be granted with studies versus placebo while pertinent comparators exist. This was the case for radium Ra223 dichloride, indicated in treatment of adults with castration-resistant prostate cancer. In 2014, this drug was granted a substantial SMR and an ASMR IV with placebo controlled evidence while three comparative therapies were available: two radiopharmaceuticals and abiraterone acetate assessed by the CT in 2012. The CT highlighted that the choice of placebo could be discussed due to the existence of these therapies.

The case of axitinib, indicated in advanced renal cell carcinoma after failure of prior treatment with sunitinib or a cytokine, illustrates that the CT might grant an ASMR on the overall study population despite the fact that the comparator had not a MA in one of the subgroups and that the study
Fig. 6 OS results and ASMR. *OS as primary or secondary endpoint. Note: Data reported for initial CT assessment (26 drugs indicated in solid tumours, 20092014). Negative OS results $=$ non significant results were found on OS. Positive OS results $=$ significant results were found for OS
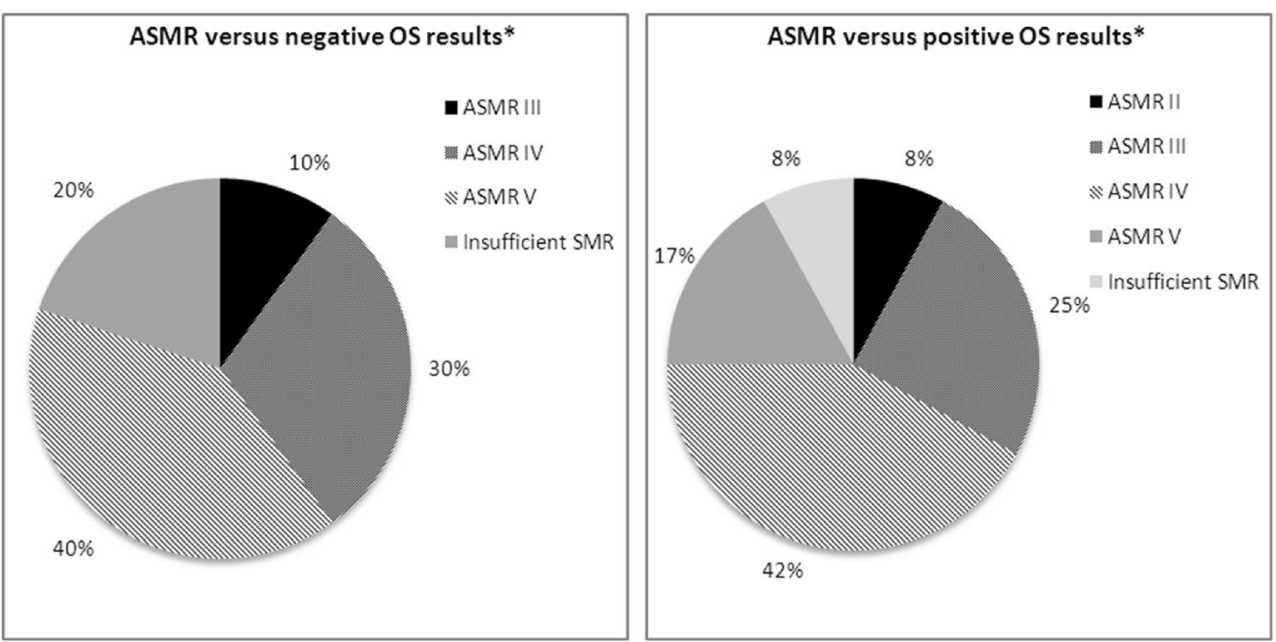
results differed between subgroups. Axitinib was granted a substantial SMR and ASMR IV in 2013 versus sorafenib, the active comparator used in the pivotal study. The results of this study showed a gain of 2 months in median PFS with axitinib versus active comparator in the overall study population - which was considered as modest - and no difference in OS. The study showed a gain of 5.6 months in median PFS with axitinib versus active comparator in the subgroup of patients after failure or prior treatment with cytokine, and of 1.4 months in the subgroup of patients after failure or prior treatment with sunitinib. The CT pointed out some methodological weaknesses in the study, i.e. open design, sample size adjustment during the study, comparator used with only a MA after failure of prior treatment with cytokine (rarely used in first-line in clinical practice); therefore, the comparison with this drug did not allow the evaluation of the therapeutic benefit of axitinib as second-line treatment after the failure of sunitinib (main first-line treatment in clinical practice).

In 2013, pazopanib was scored with a low SMR and an ASMR V during a new assessment as a first-line treatment for advanced renal cell carcinoma, after it was decided in 2010 that the clinical benefit of this drug was insufficient. The CT changed its decision following new data submission even if doubts remained on the non-inferiority to the comparator and that alternative medicinal products existed:

- the non-inferiority results were not confirmed as the sensitivity analysis (performed in the per-protocol population) did not corroborate the non-inferiority results found in the intention-to-treat population,

- the clinical significance of the non-inferiority threshold defined in the protocol was considered too large (reduction in efficacy of 2.2 months' PFS),

- the acceptable reduction in efficacy in this study was not counterbalanced by a gain, such as safety.

The case of aflibercept indicated in metastatic colorectal cancer, shows the inconsistency between the clinical data provided and the opinion issued by the $\mathrm{CT}$ in 2013. Aflibercept showed a modest efficacy with a gain of 1.44 months in median OS and of 2.23 months in median PFS versus placebo. In addition, the drug had safety issues which led patients to discontinue the treatment because of adverse events twice as frequent as with placebo (26.8 \% versus $12.1 \%)$. Despite all these weaknesses, the efficacy/adverse effects ratio was considered as high by the CT and the drug got scored with a substantial SMR and an ASMR V.

\subsection{Outputs of the Expert Board Meeting}

Many issues related to current and future trends in HTA of oncology drugs in France emerged during the meeting and are described below.

\subsubsection{Considerations for the Clinical Development}

Targeted Therapies The experts pointed out the important development of personalized medicine in oncology during the last decade. Targeted therapies acting on specific molecular targets are based on drug/diagnostic test associations which help to identify and select patients who are more prone to respond to the treatment, so as to treat only the subpopulation that will benefit from it, therefore increasing treatment efficacy and reducing patient exposure to potential side effects/ toxicity.

From the experts' point of view, tailored therapies raise many challenges in terms of strategic positioning, ethics and clinical trial design.

Strategic Positioning and Ethics Targeted therapies are designed and prescribed for appropriate target patients identified by their status for a specific marker. The targeted therapies may present different levels of benefit in different populations, i.e. very significant added value in small populations and significant added value in larger populations. In that case, two strategic positioning options can be considered: the manufacturer can choose either to enter a niche market first, and then to file for extensions of indications, or to enter a large market directly. The experts stressed that if the first option is considered, this could raise ethical concerns as it prevents access to a larger population who might benefit from the product too.

The strategic positioning choice may be in the future challenged by the CT and potential for future extensions of indications will be taken into account in the $\mathrm{CT}$ decision. The $\mathrm{CT}$ may in the future request studies in a broader population to assess the differential benefit in a restricted population.

Clinical Trial Design Increasingly breakthrough therapies will reach the market with little evidence and a very high estimate benefit and high uncertainty putting HTA and payers in front of a complex dilemma. The experts highlighted the importance of ATUs as a source to generate data to support application at time of HTA as well as a lever for pricing negotiation. The experts estimated that coverage with evidence development (with or without an escrow agreement) might be more and more considered to manage this uncertainty.

Regarding the companion diagnostic test, the experts highlighted that validation methods of these tests will add burden for the development of targeted therapies. In the guidance entitled "Companion diagnostic test associated with a targeted therapy: definitions and assessment method" [29], the HAS presented its principles to assess the clinical utility diagnostic tests associated with treatments. The HAS requires a design to demonstrate at the same time that the treatment is effective in positive biomarker patients and has no clinical benefit in negative biomarker patients. Moreover, the experts 
noticed that companion tests are managed by the molecular genetic tests developed by the French National Cancer Institute (INCa) platform outside of the commercial ones provided by manufacturers, a typical French specificity. However, in the future, such guidelines might be obsolete. An expected major change in the paradigm may be the use of biomarkers as one piece of information among a broad range of genomic tests making unavoidable the use of algorithms for deciding on the optimal chemotherapy.

Experts underlined that targeted therapies showed important benefit on OS but this outcome would be more and more complex to assess due to increased survival in oncology in general. The experts emphasized the importance to robustly validate PFS as a predictor of OS.

They also pointed out to the fact that clinical trials would increasingly include crossover in their design. The HAS will likely be late in adopting statistical models for adjusting for cross over as the CT is still very clinically oriented and resistant to innovative statistical methodologies, as already seen for network meta-analyses for example.

Methodological Considerations The development of drugs is rapidly evolving making the choice of the comparator used in clinical trials outdated at the time of assessment. In this environment, the experts stressed the increasing importance of indirect comparisons. To enable indirect comparison, the design of clinical studies will have to allow matching similar inclusion/exclusion criteria, endpoints, duration, etc.; even if they are not the one considered for the primary endpoint of that study. This would enable performing high quality indirect comparisons.

The experts expected in the future that life extension of at least 3 months with evidence of maintained or improved quality of life will be required. Consistency of primary and secondary endpoints will be important.

\subsubsection{Transferability and Generalisability}

The experts highlighted the increasing scrutiny for jurisdictional and clinical routine practice transferability of clinical trials. It is expected to become one of the most complex issues to address in the future for applicants to the HAS, and especially when important differences in availability of treatment and practice across jurisdictions exist.

The experts pointed out that in the years to come, MA will be more and more based on phase 2 studies with well characterized populations. To manage uncertainty, the experts estimated that a growing number of real-life studies with specific objectives will be required in the future. Real-life studies will most probably involve studies on effectiveness and drug usage (e.g. dose, treatment duration, starting/stopping rules and target population). They also stressed the importance to follow patients from ATU cohorts after MA to collect real-life data to address HTA requirements.

\subsubsection{Health Economic Assessment}

Health economic assessment is still immature in France and will continue to develop. Methodological requirements are expected to increase in the coming years.

Cost per QALY is definitely accepted as the reference endpoint, and an unofficial post-hoc incremental costeffectiveness ratio (ICER) threshold would likely be established based on experience.

Models are expected to be simple robust and straightforward. Markov model with three health states (progression, free progression and death) is expected to remain the reference in oncology.

\subsubsection{New Approaches in Drug Assessment}

In March 2014, the EMA initiated a pilot project on adaptive licensing. However, from the experts' opinion, it is very unlikely to affect market access in the short term. The apparent complexity of the methodology and the strong reliance on deterministic statistics of the CT may create additional hurdles for access to these products in France. Since 2011, a reform of drug assessment is under discussion within the HAS to replace the SMR/ASMR by a new therapeutic index: Index Thérapeutique Relatif, ITR. However, the experts considered that ITR was far to be implemented. The General Inspectorate of Social Affairs (Inspection Générale des Affaires Sociales, IGAS) report related to ITR implementation considered that although a change is requested, ITR was not ready to take over and still needed some maturation and adjustment [30].

\section{Discussion}

\subsection{Health Technology Assessment Trends in France}

In France, the CT opinion is one of the main drivers for pricing and reimbursement of medicines. One of the French philosophical concepts is to enable access to the most effective care, including medicines, for all patients across the territory. As a Bismarck-type social security system, French healthcare system principles are to grant the same level of healthcare access to the whole population through contribution and redistribution [31]. Especially in the field of oncology products, the primary aim of the Cancer Plan 2014-2019 is "to cure more patients, by promoting early diagnosis and guaranteeing access to all to innovations" [20].

In a cost-constrained environment, the CT has a moral responsibility to guarantee the sustainability of the national health insurance system while making its decisions although 
it is not its mandate. Moreover, informal interactions are seen between the $\mathrm{CT}$ and the pricing Committee (CEPS). In this context, CT requirements are evolving with stricter rules. First, an increasing number of products targeting severe conditions are denied reimbursement. The SMR score is increasingly driven by the drug benefit-risk ratio and the existence of therapeutic alternatives, while disease severity is less considered [28]. Then, if different decision criteria to acknowledge or not an innovative product are not new, an increasing request for robust evidence in terms of study methodology is observed. Moreover, transferability of clinical data to real-life settings is becoming critical for the CT, with an increasing demand for these data conditioning price and reimbursement decisions (in terms of conditions of use, effectiveness, ICER in real life, safety and tolerability, use of healthcare resources). The impact on the healthcare organization is also more and more important in the whole decision process. Finally, even if $\mathrm{CT}$ assessments are only based on clinical criteria, concomitant filing of dossier at the CT and the CEPS, and considering informal communication between both committees, the CT might have access to the price submitted by the company influencing its decision.

Driven by budget constraint, there has been an increase in government control and regulation as seen with the introduction of health economic assessment of health products in France in 2012 [32]. However, health economic assessment has not been designed as a tool to manage the economic constraint, but as a decision-making support tool limited to price negotiations, demonstrating the French government's willingness to prevent health economic criteria to drive reimbursement [31].

HTA in France is mainly based on clinical assessment as drugs with an ASMR IV or V represent the majority of drug assessed by the CT and are not supposed to be eligible for health economic assessment (For example, in 2013, for a first drug assessment, 1 ASMR I, 0 ASMR II and 8 ASMR III were granted for 10 ASMR IV and 148 ASMR V [33]). However, some of these drugs for which the manufacturer would claim an ASMR II or III, will be eligible for health economic assessment but this assessment should not have any impact on pricing decision as these drugs are not expected to have an impact on the pharmaceutical budget according to French regulation [34].

In the future, it is expected that pricing and reimbursement decisions will likely be more and more driven by budget constraint rather than by existing rules. There is a shift towards a rather reactive than proactive system in which ad hoc policy decisions are taken on a case-by-case basis. As it has been initiated with the Solvadi ${ }^{\circledR}$ (sofosbuvir) case, the experts expect an increasing cross-countries payers' collaboration to manage healthcare budget pressure and intervention of parliament to contain a budget for a specific drug or therapeutic class.
The unpredictability of CT decisions is mainly driven by two motives. First, the multiplicity of factors affecting a decision makes it difficult to appreciate, in the absence of a clear reference case, the role of one factor such as OS or PFS from the others, even if they are considered as predominant in impacting the scoring. Then, the fact that decision and appraisal are not dissociated in France like in the UK makes it difficult to separate the facts from the judgement. The judgement is deliberative and therefore not accessible if you do not participate in the CT. Separating the assessment from the appraisal would enhance decision transparency.

\subsection{Challenges for Oncology Products to Provide Appropriate Evidence}

The development of new oncology therapies is facing multiple challenges to generate information expected from the HTA perspective.

First, the progress in cancer led to longer survival times, making OS a difficult endpoint to reach. If PFS, used as a surrogate measure in an increasing number of clinical studies for patients with advanced solid tumours, is currently accepted by the CT [35], OS remains a key endpoint for decision-making. Providing quality of life on top of life extension is also becoming critical information to allow ensuring that at least quality of life is not degraded even if not necessarily improved as it is a progressive condition.

Then, patient crossover, i.e. switching from reference arm to active arm is often an issue in oncology trials, as it may happen before OS is reached leaving the pivotal endpoint not available. Several statistical methods for adjusting for crossover were developed [36]. The experience shows that France is reluctant to these types of models and takes few considerations of such models in its decision-making.

Another challenge is the fast development of available therapeutic alternatives, often making obsolete the development of the comparator used in the development program of the drug. It will make it unavoidable for the $\mathrm{CT}$ to accept indirect comparisons.

Finally, drug development in oncology benefits from molecular genetics. Biomarkers allow selecting patient groups susceptible to respond to a given therapy. For one specific type of cancer, molecular subsets of cancers can be identified [37] which might be classified as "rare cancers". Therefore, the development of biomarkers and associated therapies require rethinking the design of clinical trials to demonstrate the clinical utility of the biomarker. However, such studies might be difficult to implement if the biomarker identification arrives late in the development process (sometimes not before the phase III clinical trial results), and also due to the ethical issues raised of testing biomarker in negative patients, for a therapy that may not benefit them [38]. 
The development of hundreds of genomic markers in routine practice, will lead to new ways of treating oncology patients. In the future, the value, indication, usage and positioning of oncology products may change fast many times over the product life-cycle and this will also concern off-patent products making it increasingly complex to appreciate the value of new therapies at time of launch.

New targeted therapies may, in some cases, provide large benefit in small trials leading to early approval with very limited evidence not always compatible with HTA bodies' expectations. Indeed, added value assessment will no longer be supported by conventional and adequately powered randomized controlled trials and uncertainty will need to be addressed post-launch [39]. The recent international concept of "adaptive pathways" defined as a prospective planned and flexible approach to licensing and coverage of drugs and learning from real-world data, is expected to be the only viable access route for such therapies [39]. In this context, managed entry agreements and especially coverage with evidence development schemes, as well as drug price conditionality are expected to increase in the years to come to minimize payers' uncertainty while allowing access to new therapies. More coordination is expected between the European regulators and payers for evidence generation, and the process is already on going with early dialogues initiated between the European Medicines Agency and the European network for HTA (EUnetHTA). It will become very important for companies developing new drugs in oncology to address the cross jurisdiction transferability as well as the transferability to the real world of the clinical trials outcomes.

Moreover, new types of clinical trials are emerging in France, known as clinical trials using genomic profiling (e.g. AcSé program $[40]^{2}$, or SAFIR program $\left.[41]^{3}\right)$. These innovative trials imply new methodologies, such as integrated protocols (several phases in only one trial), use and comparisons of several treatments without MA, new endpoints as the percentage of complete remission and adaptive designs [42]. There is a common willingness of all actors in the oncology field to sustain innovation as seen with increasing private and public partnerships.

\footnotetext{
${ }^{2}$ AcSé Programme has recently been launched by the French National Cancer Institute (INCa) and aims to extend the indications of the best medications currently available for certain cancers. It also enables secure access to off-label targeted therapies to patients for whom validated therapies have failed. INCa identifies one institution to sponsor the study and requests the pharmaceutical company marketing the targeted therapy to provide it for free for a phase 2 trial. In case efficacy is demonstrated, it will enable to identify new potential indications to be developed by the pharmaceutical company.

${ }^{3}$ The SAFIR programme has been developed to demonstrate the feasibility and interest of molecular approach in the therapeutic management of patients. SAFIR trials are set up to assess technical feasibility of genomic profiles in clinical practice (i.e. therapeutic choice based on tumour genomic profile). The pharmaceutical company AstraZeneca has adhered to this program and provided all targeted therapies of its pipeline for the trials.
}

\subsection{Accessibility of Oncology Products in France}

In France, the accessibility of oncology products remains high as most innovative products reach the market at negotiated condition agreeable for both payers and industry. The funding on top of DRG was an incentive for hospitals to widely use innovative products. Indeed, if the hospital buys medicines at a lower price than the declared price, the price difference will be shared between sickness funds and the hospital [43]. This incentive was decreased with the social security funding law for 2015 (decrease of some DRG in case of concomitant prescription of medicines of «Liste en sus ») [44]. Even if hospitals are requested to evidence proper use of such products, it remains almost unrestricted for hospitals to use innovative oncology products.

HTA does not appear in France as a tool to restrict the access of oncology products but may significantly affect the net price reachable by industry explaining the potential delay in pricing negotiations.

\section{Conclusion}

The French system remains committed to its values and philosophy (access of all innovations for everybody) which are threatened by the increasing launch of innovative therapies and the budget constraint. To counteract these threats, the CT has systematically increased its level of requirements to acknowledge innovation. French law makers sharing the same concerns, introduced health economic assessments. The oncology area is one of the main fields of interest in research and development with a significant number of innovative therapies expected to reach the market in the years to come. These products are expected to bring an increasing added value by targeting very specific populations and to change the standard clinical development of oncology medicines. To face challenges in the field of oncology products, the current French HTA process should evolve to enable a more specific approach of this very innovative therapeutic area. Without the development of new considerations for the oncology field (such as uncertainty management), the current HTA process in France may become disconnected from reality and lead to delay in access of new innovative therapies. Both HTA decision framework evolution and revision of the current pricing process should be considered in France to cope with these new challenges. However, although HTA impacts net prices of oncology products, it has limited impact on patient access.

\section{Compliance with Ethical Standards}

The manuscript does not contain clinical studies or patient data.

Funding This study was funded by Janssen France. Creativ-Ceutical was contracted by Janssen France for conducting this research, writing and reviewing the manuscript. 
Conflict of Interest EB, DS and M-LB are employees of Janssen France. CR is an employee of Creativ-Ceutical. MT has received fees (including fees for conducting this research) from and is a regular consultant to Creativ Ceutical and has received personal fees from, and is a consultant for, several pharmaceutical companies and health authorities in health economics, pricing and market access. IB has received personal fees from Janssen France and Roche, has served as a board member at Janssen France and has received personal fees from Creativ-Ceutical for conducting this research. CC has received personal fees from Novartis, Boehringer, Lilly and Roche, has served as a board member at BMS, MSD, Lilly, Roche and as a consultant for Boehringer, Lilly, Amgen and Novartis and has received fees from Creativ-Ceutical for conducting this research

Open Access This article is distributed under the terms of the Creative Commons Attribution-NonCommercial 4.0 International License (http:// creativecommons.org/licenses/by-nc/4.0/), which permits any noncommercial use, distribution, and reproduction in any medium, provided you give appropriate credit to the original author(s) and the source, provide a link to the Creative Commons license, and indicate if changes were made.

\section{References}

1. Institut National du Cancer (INCa): Les cancers en France. Les Données. http://www.e-cancer.fr/publications/69-epidemiologie/ 824-les-cancers-en-france-edition-2014 (2014). Accessed 2 April 2015 .

2. Institut de veille sanitaire (InVS): Bulletin épidémiologique hebdomadaire. $\mathrm{N}^{\circ} 22$. http://www.invs.sante.fr/beh/2011/22/beh_ 22 2011.pdf (2011). Accessed 2 April 2015.

3. Institut National du Cancer (INCa): Incidence et mortalité des cancers en France métropolitaine. https://lesdonnees.e-cancer.fr/lesfiches-de-synthese/29-incidence-mortalite/38-ensemble-descancers/22-incidence-mortalite-france.html (2015). Accessed 2 April 2015.

4. Luengo-Fernandez R, Leal J, Gray A, Sullivan R. Economic burden of cancer across the European Union: a population-based cost analysis. Lancet Oncol. 2013;14:1165-74.

5. Allodocteurs.fr: Cancer: pour une réévaluation des prix des traitement. http://www.allodocteurs.fr/actualite-sante-cancer-pourune-reevaluation-des-prix-des-traitements-11720.asp?1=1 (2013). Accessed 2 April 2015.

6. Slate.fr: La facture immorale des nouveaux médicaments anti-cancer. http://www.slate.fr/france/79671/le-prix-immoral-desnouveaux-medicaments-anti-cancer (2013). Accessed 2 April 2015.

7. Mutualité Française: Moraliser les prix des anticancéreux. http:// www.mutualite.fr/L-actualite/Kiosque/Revues-de-presse/ Moraliser-les-prix-des-anticancereux (2015). Accessed 2 April 2015.

8. Le Figaro.fr: Cancer: le coût des médicaments explose. http://sante. lefigaro.fr/actualite/2012/07/05/18606-cancer-cout-medicamentsexplose (2015). Accessed 2 April 2015.

9. Le pharmacien de France: Le prix d'une vie. http://www. lepharmacien.fr/decembre-2013/enqu-te-le-prix-d-une-vie.html (2013). Accessed 2 April 2015.

10. Le Figaro.fr: Cancer: pourquoi les prix des médicaments ont-ils augmenté. http://sante.lefigaro.fr/actualite/2012/07/05/18603cancer-pourquoi-prix-medicaments-ont-ils-augmente (2012). Accessed 2 April 2015.
11. Le Monde: Pour l'IGAS, les prix des anticancéreux sont trop favorables aux laboratoires. http://www.lemonde.fr/sante/article/2012/ 07/10/pour-l-igas-les-prix-des-anticancereux-sont-trop-favorablesaux-laboratoires_1731608_1651302.html (2012). Accessed 2 April 2015.

12. Economie matin: Le remboursement des traitements contre le cancer: un énorme gaspillage de fonds publics. http://www. economiematin.fr/news-sante-cancer-traitement-rembourses-secu (2013). Accessed 2 April 2015.

13. Le Monde: Cancer: l'épineuse question du prix des traitements. http://www.lemonde.fr/sciences/article/2014/06/03/cancer-1epineuse-question-du-prix-des-traitements_4430785_1650684 html (2014). Accessed 2 April 2015.

14. Rouëssé J, Bouvenot G, Meyer F, Rochaix L, Tubiana M, Woronoff-Lemsi C, et al. Mise au point sur la prescription des molécules onéreuses en cancérologie. Bull Acad Natl Med. 2011;195:699-727.

15. Comité éthique et cancer: Du bon usage des molécules onéreuses en cancérologie et avis sur les choix inhérents aux contraintes imposées par le coût de ces molécules. Avis n ${ }^{\circ} 17$ du 30 septembre 2011. http://www.ethique-cancer.fr/phoenixws/detailavis/topic-1/ article-81/avis-n-17-du-30-septembre-2011.html (2011). Accessed 2 April 2015.

16. Duhamel G, Morelle A, Inspection générales des affaires sociales (IGAS): Evaluation du dispositif de financement des médicaments en sus des prestations d'hospitalisation dans les établissements de santé. http://www.annuaire-secu.com/pdf/rapportIGAS-evaluationdispositif-medicament-en-sus.pdf (2012). Accessed 2 April 2015.

17. Fondation ARC pour la recherche sur le cancer: Les révolutions de la recherche sur le cancer. 15 années de progrès, 12 défis pour l'avenir. http://www.fondation-arc.org/Information-du-public/lesrevolutions-de-la-recherche-sur-le-cancer-15-annees-de-progres12-defis-pour-l-avenir.html (2014). Accessed 2 April 2015.

18. Experts in chronic myeloid leukemia. The price of drugs for chronic myeloid leukemia (CML) is a reflection of the unsustainable prices of cancer drugs: from the perspective of a large group of CML experts. Blood. 2013;121:4439-42.

19. La Croix: Les médicaments du cancer atteignent un niveau de prix immoral. Entretien avec Jean-Paul Vernant. http://www.la-croix. com/Actualite/France/Les-medicaments-du-cancer-atteignent-unniveau-de-prix-immoral-2013-11-06-1056577 (2013). Accessed 2 April 2015

20. Plan cancer 2014-2019. http://www.e-cancer.fr/toutes-lesactualites/2755-plan-cancer/8644-lancement-du-plan-cancer2014-2019 (2014). Accessed 2 April 2015.

21. Institut de recherche et documentation en économie de la santé (IRDES): Historique des Lois de financement de la Sécurité sociale en France. http://www.irdes.fr/EspaceDoc/DossiersBiblios/ LoisFinancementSecu.pdf (2013). Accessed 2 April 2015.

22. Legifrance: Loi $^{\circ}{ }^{2}$ 2011-1906 du 21 décembre 2011 de financement de la sécurité sociale pour 2012. http://www.legifrance.gouv.fr/ a f f i c h T e x t e. d o ? c i d T e x t e = JORFTEXT000025005833\&categorieLien=id (2011). Accessed 2 April 2015.

23. Legifrance: Loi $n^{\circ}$ 2011-2012 du 29 décembre 2011 relative au renforcement de la sécurité sanitaire du médicament et des produits de santé. http://www.legifrance.gouv.fr/affichTexte.do?cidTexte= J O R F T E X T $000025053440 \&$ c a t e gorie Li e n = id\#JORFARTI000025053734 (2011). Accessed 2 April 2015.

24. Legifrance: Loi $n^{\circ}$ 2013-1203 du 23 décembre 2013 de financement de la sécurité sociale pour 2014. http://www. legifrance.gouv.fr/affich Texte.do? cid Texte $=$ JORFTEXT000028372809\&dateTexte $=\&$ categorieLien $=\mathrm{id}$ (2013). Accessed 2 April 2015.

25. Ministère du travail de l'emploi et de la santé: Rapport 2011 au Parlement sur la tarification à l'activité (T2A). Annexe 1 
Recommandation 2010-25 du Conseil de l'hospitalisation, relative à la gestion de la liste en sus. http://www.sante.gouv.fr/IMG/pdf/ Rapport_T2A_au_Parlement_2011_transmis_1509_11.pdf (2010). Accessed 2 April 2015.

26. Inspection générale des finances et inspection générale des affaires sociales: Propositions pour la maîtrise de l'ONDAM 2013-2017. http://www.sante.gouv.fr/IMG/pdf/Rapport_ONDAM-IGAS-IGF_ juin2012.pdf (2012). Accessed 2 April 2015.

27. Fédération hospialière de France: Evaluation de la T2A. Rapport de la FHF. http://fichiers.fhf.fr/documents/Rapport-finances-04juin. pdf (2013). Accessed 2 April 2015.

28. Rémuzat C, Toumi M, Falissard B. New drug regulations in France: what are the impacts on market access? Part 1 - overview of new drug regulations in France. JMAHP. 2013;1:20891.

29. Haute Autorité de Santé (HAS): Test compagnon associé à une thérapie ciblée: définitions et méthode dévaluation. http://www. has-sante.fr/portail/upload/docs/application/pdf/2014-04/guide meth court test cpagnon vd.pdf (2014). Accessed 2 April 2015.

30. Inspection générale des affaires sociales (IGAS): Révision des critères d'évaluation des produits de santé en vue de leur prise en charge par l'assurance maladie Analyse de l'Index thérapeutique relatif (ITR) proposé par la HAS. Mission d'appui à la Direction de la sécurité sociale. http://www.igas.gouv.fr/IMG/pdf/2013099R2 Rapport ITR.pdf (2013). Accessed 15 May 2015.

31. Massetti M, Aballéa S, Videau Y, Rémuzat C, Roïz J, Toumi M. A comparison of HAS \& NICE guidelines for the economic evaluation of health technologies in the context of their respective national health care systems and cultural environments. JMAHP. 2015;3: 24966.

32. Legifrance: Décret $n^{\circ} 2012-1116$ du 2 octobre 2012 relatif aux missions médico-économiques de la Haute Autorité de santé. http://www.legifrance.gouv.fr/affichTexte.do?cidTexte= JORFTEXT000026453514\&categorieLien=id (2012). Accessed 2 April 2015.

33. Haute Autorité de Santé (HAS): Rapport d'activité 2013. http:// www.has-sante.fr/portail/jcms/c 1267546/fr/rapport-annuel-dactivite-2013 (2014). Accessed 2 A pril 2015.

34. Rémuzat C, Toumi M, Falissard B. New drug regulations in France: what are the impacts on market access? Part 2 impacts on market access and impacts for the pharmaceutical industry. JMAHP. 2013;1:20892.
35. Korn RL, Crowley JJ. Overview: progression-free survival as an endpoint in clinical trials with solid tumours. Clin Cancer Res. 2013;19:2607-12.

36. Jönsson B, Ramsey S, Wilking N. Cost effectiveness in practice and its effect on clinical outcomes. J Cancer Policy. 2014;2:12-21.

37. Institut National du Cancer (INCa), Fabien Calvo: Personalized medicine, a nationwide initiative for an equal access to cancer treatment in France. Presentation. http://ec.europa.eu/research/health/ pdf/event06/13052011/fabien-calvo_en.pdf (2011). Accessed 2 April 2015.

38. Marquet P, Longeray PH, Barlesi F, Ameye V, Auge P, Cazeneuve $B$, et al. Translational research: precision medicine, personalized medicine, targeted therapies: marketing or science? Therapie. 2015;70:11-9.

39. Eichler HG, Baird LG, Barker R, Bloechl-Daum B, BorlumKristensen F, Brown J, et al. From adaptive licensing to adaptive pathways: delivering a flexible life-span approach to bring new drugs to patients. Clin Pharmacol Ther. 2015;97:234-46.

40. Institut National du Cancer (INCa): Le programme AcSé. http:// www.e-cancer.fr/recherche/recherche-clinique/le-programme-acse (2013). Accessed 2 April 2015.

41. Institut National du Cancer (INCa): Résultats de SAFIR 01 : premiers résultats d'une étude clinique de médecine personnalisée à large échelle. http://www.e-cancer.fr/presse/7141-resultats-desafir-01-premiers-resultats-dune-etude-clinique-de-medecinepersonnalisee-a-large-echelle (2012). Accessed 2 April 2015.

42. Agence Nationale de Sécurité du Médicament et des Produits de Santé: Conduite des essais cliniques de médicaments en onco/ hématologie ciblés, guidés par la génomique. http://ansm.sante.fr/ var/ansm_site/storage/original/application/ 1c7c13b95daa7804f72df7e589867a86.pdf (2014). Accessed 2 April 2015.

43. Delcroix Lopes S, Marty C, Berdai D.: PHIS Pharma Profile France 2011. http://whocc.goeg.at/Literaturliste/Dokumente/ CountryInformationReports/PHIS_Pharma\%20Profile\%20FR 2011_final.pdf (2011). Accessed 16 May 2015.

44. Legifrance: Loi ${ }^{\circ}$ 2014-1554 du 22 décembre 2014 de financement de la sécurité sociale pour 2015. http://www. legifrance.gouv.fr/affich Texte.do? cidTexte= JORFTEXT000029953502 (2014). Accessed 16 May 2015. 